\title{
Medical Ultrasound Practice in Developing Countries: Example of Togo
}

\author{
Pihou Gbande ${ }^{1 *}$, Kokou Adambounou1, Lantam Sonhaye1, Lama Kegdigoma Agoda-Koussema², \\ Komlavi Adjenou ${ }^{1}$
}

${ }^{1}$ Radiology Department, Campus Teaching Hospital, Lomé, Togo

${ }^{2}$ Radiology Department, Sylvanus Olympio Teaching Hospital, Lomé, Togo

Email: *gbandepihou@yahoo.fr

How to cite this paper: Gbande, P., Adambounou, K., Sonhaye, L., Agoda-Koussema, L.K. and Adjenou, K. (2018) Medical Ultrasound Practice in Developing Countries: Example of Togo. Open Journal of Radiology, 8, 217-222.

https://doi.org/10.4236/ojrad.2018.84025

Received: October 10, 2018

Accepted: November 5, 2018

Published: November 8, 2018

Copyright $\odot 2018$ by authors and Scientific Research Publishing Inc. This work is licensed under the Creative Commons Attribution International License (CC BY 4.0).

http://creativecommons.org/licenses/by/4.0/

(c) (i) Open Access

\begin{abstract}
Background: Ultrasound has become the most widely practiced medical imaging examination even in developing countries because of its non-irradiating, non-invasive nature and its relatively affordable cost. Objective: The objective of this study was to review the practice of medical ultrasound in Lomé city. We carried out a descriptive cross-sectional study using the pre-established fact sheets. It took place from 16 August to 30 November 2013 in the healthcare facilities of the city of Lomé. Results: A total of 47 centers were surveyed, including 14 public centers and 33 private centers. The ultrasound scanners were mostly acquired in the new state $(59.6 \%)$ with only $34.1 \%$ of these ultrasound scanners equipped with the Doppler mode. There were 3 ultrasound scanners (6.4\%) that had a 3D probe. Radiologists were the ones who carried out most of the ultrasound examinations in public centers, while in private they accounted for half of the performers (45.5\%). Physicians enrolled in a specialty in radiology played a significant role in these private structures, accounting for $24.2 \%$ of performers. Cardiac ultrasound was performed only in 2 centers (4.2\%). The ultrasound report was available in all public centers using the pre-established and standardized forms. The qualification of sonographers and the status of ultrasound scanners are relatively acceptable. Conclusion: Ultrasound scanners were mostly acquired in new condition. Radiologists remained the ones who carried out the largest number of ultrasound examination in Lomé.
\end{abstract}

\section{Keywords}

Ultrasound Practice, Sonographer, Radiologist, Togo

\section{Introduction}

Ultrasound has become the most widely practiced medical imaging examination 
because of its non-irradiating, non-invasive nature and its relatively affordable cost. It is now the second step in the management of patients after clinical examination, in particular in emergencies [1].

Until 1970, most ultrasound examinations were a simple dating of pregnancy in obstetrics and were performed almost by radiologists [2]. Progressively, this practice of ultrasound has spread to other areas of medicine especially with the advent of new applications of ultrasound since the 1980s. The use of ultrasound has developed in medical practice clinic in different specialties.

In Togo, the first ultrasound was performed in 1987 and since then its accessibility has been increasing even in the rural areas. But we lack studies that really evaluate the conditions under which these ultrasounds are performed. It is with this in mind that we undertook this study in order to review the practice of ultrasound in Togo, by studying the profile of performers, the characteristics of ultrasound scanners and by analyzing the mode of ultrasound scans reporting.

\section{Materials and Methods}

We carried out a descriptive cross-sectional study using the pre-established fact sheets. It took place from 16 August to 30 November 2013 in the healthcare facilities of the city of Lomé (capital city of Togo).

The two teaching hospitals of Lomé (SylvanusOlympio and Campus), the regional hospital and the 4 district hospitals of the Lomé-commune health region were included in this study. As the Lomé health region was divided into five districts, a selection of 3 medical centers was carried out per district and 25 private medical clinics were drawn to participate in the survey.

Non-standard health facilities were excluded from the survey.

So, there were 47 health facilities surveyed out of 125 facilities.

We previously carried out a data collection sheet on the ultrasound centers, which concerned:

- The center: the place (district), the legal form (private or public),

- Characteristics of the scanners: the brand, condition to purchase (new or used), types of probes, Doppler coupling or not,

- The qualification of the performer,

- The examinations carried out and the method of reporting.

This data was analyzed with the Epi Info 3.5.3 software.

\section{Results}

A total of 47 centers were surveyed, 14 public centers and 33 private centers.

Most of the ultrasound scanners were acquired in new condition. All ultrasound machines had a convex probe, while more than half did not have a linear probe. More than $2 / 3$ of scanners were not coupled to the Doppler (Table 1).

Radiologists were the ones who carried out most of the ultrasound examinations in public centers $(\mathrm{n}=10 ; 71.4)$, while in private they accounted for half $(\mathrm{n}=15 ; 45.5 \%)$. Physicians enrolled in radiology specialty played a significant 
Table 1. Characteristics of ultrasound scanners.

\begin{tabular}{cccc}
\hline & & Number & Percentage \\
\hline Statement of purchase & New & 28 & $59.6 \%$ \\
& Handled & 19 & $40.4 \%$ \\
Probe type & Total & 47 & $100 \%$ \\
& Convex & 47 & $100 \%$ \\
& Endocardial & 24 & $51.1 \%$ \\
& Linear & 18 & $38.3 \%$ \\
Doppler coupling & 3D, 4D & 3 & $6.4 \%$ \\
& No & 31 & $65.9 \%$ \\
& Yes & 16 & $34.1 \%$ \\
\hline
\end{tabular}

role in these private structures, accounting for $(\mathrm{n}=10 ; 24.2 \%)$ of performers (Table 2).

No general practitioner or paramedical health worker performed ultrasound in the centers visited.

Obstetric, pelvic and abdominal ultrasounds were performed in all centers while cardiac ultrasound was performed only in 2 centers that were private (Table 3).

In all the centers the report was in the majority of cases done using the pre-established and standardized forms (Table 4).

\section{Discussion}

\subsection{Methodology}

This study, covering an overview of the practice of ultrasound, was carried out in 47 health facilities, including the two Teaching Hospitals, which are the reference centers of the country. This is the first study carried out in this framework in our country. It will serve as a repository of data on this subject. We have made a reasoned choice based on a sample of health centers in Lomé. Such a choice may constitute a limit for this study since it does not take into account all the health centers in Lomé. However, given the selection criteria for this sample, we consider that it is validly representative of the health centers of the city of Lomé.

\subsection{Ultrasound Scanners and Sonographers Profile}

Ultrasound equipment was usually acquired in new condition. This can be explained by the appearance on the Togolese market of Chinese branded ultrasound scanners which are at very affordable prices compared to ultrasound scanners of European and American origin.

Our study revealed that all ultrasound machines had a convex probe, while only $37.9 \%$ of ultrasound scanners had a linear probe. This finding differs little from that of Girisgin et al. in Turkey who found that all ultrasound scanners 
Table 2. Distribution of the qualification of the director of examinations according to the legal form of the ultrasound centers.

\begin{tabular}{ccccc}
\hline & \multicolumn{2}{c}{ Public } & \multicolumn{2}{c}{ Private } \\
\hline & $\mathrm{N}$ & $\%$ & $\mathrm{~N}$ & $\%$ \\
\hline Radiologist & 10 & $71.4 \%$ & 15 & $45.5 \%$ \\
$\begin{array}{c}\text { Non-radiologist specialist } \\
\text { Physician in radiology } \\
\text { specialization }\end{array}$ & 2 & $14.3 \%$ & 10 & $30.3 \%$ \\
Total & 2 & $14.3 \%$ & 8 & $24.2 \%$ \\
\hline
\end{tabular}

$\mathrm{N}=$ number; $\%=$ percentage.

Table 3. Distribution of the types of examinations carried out according to the legal form of the ultrasound centers.

\begin{tabular}{ccccc}
\hline & \multicolumn{2}{c}{ Public } & \multicolumn{3}{c}{ Private } \\
\hline & N & $\%$ & N & $\%$ \\
\hline Obstetric & 14 & $100 \%$ & 15 & $45.5 \%$ \\
Pelvic & 14 & $100 \%$ & 10 & $30.3 \%$ \\
Abdomen & 14 & $100 \%$ & 8 & $24.2 \%$ \\
Cardiac & 0 & 0 & 2 & $6.1 \%$ \\
Vessels & 2 & $14,3 \%$ & 2 & $6.1 \%$ \\
Others & 3 & $21,4 \%$ & 3 & $9.1 \%$ \\
\hline
\end{tabular}

*Other: surface organs and soft tissues.

Table 4. Expression of the reporting mode according to the type of center.

\begin{tabular}{ccccc}
\hline & \multicolumn{2}{c}{ Pre-established } & \multicolumn{2}{c}{ Seizure } \\
\hline & $\mathrm{N}$ & $\%$ & $\mathrm{~N}$ & $\%$ \\
\hline Public $(\mathrm{n}=14)$ & 14 & $100 \%$ & 0 & 0 \\
Private $(\mathrm{n}=33)$ & 23 & $69.7 \%$ & 12 & $36.4 \%$ \\
Total $(\mathrm{n}=\mathbf{4 7})$ & 37 & $\mathbf{7 8 . 7 \%}$ & $\mathbf{1 2}$ & $\mathbf{2 5 . 5} \%$ \\
\hline
\end{tabular}

used in the bedside in emergency services had both convex and linear probes [3]. Our result could be explained by the fact that the most extensive explorations remained those of the deep organs (liver, kidneys, pancreas, uterus, ovaries, etc.) considered to be part of general ultrasound. It is for this reason that the WHO since the years 96 recommended that for the purchase of a general purpose ultrasound system, the standard probe should have a frequency of $3.5 \mathrm{MHz}$ [4].

Radiologists were the ones who carried out the majority of the ultrasound examinations in the public centers while in private they accounted for just under half of the performers. Physicians enrolled in radiology specialties played a significant role in these private structures. The European Society of Radiology in 2013 found a mixed result [5]. There were hospitals in which the majority of ultrasound examinations were carried out by radiologists whereas it was not the 
case in other hospitals. In our study, a radiologist alone was obliged to cover 3 to 4 ultrasound centers since until 2011, Togo had only 9 radiologists, 3 of whom were exclusively in private practice [6]. The place of doctors in radiology specialization in this practice deserves to be seriously discussed in the reflections to come to define exactly their exercise. No general practitioner or paramedic health worker performed ultrasound in all centers visited while this competency is transferred to other health professionals in other countries of Africa. This is the case for example in Senegal where general practitioners and midwives are trained in ultrasound [7]. The need to train non-radiologists in this practice in our country is therefore no longer to be demonstrated. The training of a sonographer is long: one year of minimum training for a specialty (cardiovascular, abdomen, pelvis, fetus...). In addition, for ultrasound diagnostics, the sonographer often needs the advice of another colleague who, in most cases, does not work in the same health facility or in the same city as himself, the tele-ultrasound could appear as an alternative [8].

\subsection{The Ultrasound Report Mode}

In all the visited centers, the ultrasound report was made using pre-established records. This mode allows faster editing. It is adapted to a given pathology or to an organ. This is often the case for obstetric ultrasound reports [9]. It is often handwritten in our context and does not require a secretariat. The disadvantage is that it is not often adapted to the question posed by the prescriber. Indeed, the radiological report is a written transcription, in clear and unambiguous terms, and transmission, of the different stages of the radiological examination: indications, techniques of realization, results, synthesis and medical conclusion [10]. Since ultrasound is a "dependent operator", the clinician therefore needs quality criteria to know whether he can trust the ultrasound he has in his hands or not. The length can not be standardized and should be adapted to the pathology to be described and the question asked.

\section{Conclusion}

A cross-sectional study on the panorama of the ultrasound practice in Lomé was carried out in the public and private sanitary structures of the city of Lomé. It allowed us to realize that ultrasound features were mostly acquired in new condition. Radiologists, although not exclusively performing ultrasound examinations, remained the ones who carried out the largest number of ultrasound examinations in Lomé. The ultrasound report was usually standardized.

\section{Conflicts of Interest}

The authors report no conflict of interest.

\section{References}

[1] Kirkpatrick, A., Sustic, A. and Blaivase, M. (2007) Introduction to the Use of Ultra- 
sound in Critical Care Medicine. Critical Care Medicine, 35, S123-S125. https://doi.org/10.1097/01.CCM.0000260622.26564.94

[2] Hart, A. and Dixon, M. (2008) Sonographer Role Extension and Career Development: A Review of the Evidence. Ultrasound, 16, 31-35. https://doi.org/10.1179/174313408X259382

[3] Girisgin, S.A., Cander, B., Yurumez, Y., Coskun, F., Ikizceli, I. and Akkose, S. (2008) Bedside Sonography in Emergency Departments in Turkey. Ultrasound, 16, 102-104. https://doi.org/10.1179/174313408X305056

[4] Palmer, P.E.S. (1996) Manuel d'échographie. OMS, Geneve.

[5] European Society of Radiology (ESR) (2013) Organisation and Practice of Radiological Ultrasound in Europe: A Survey by the ESR Working Group on Ultrasound.

[6] Ministère de la santé (2012) Profil en ressources humaines pour la santé du Togo.

[7] Badiane, S.M., Thiam, O., Dia, A.A., Gueye, M., Seck, S.M., Ndoye, O.L., et al. (2013) Experience of the First Continuous Medical Ultrasound Traning for General Practitioners and Midwives at Saint-Louis Health Sciences. Rev Cames Santé, 1, 57-65.

[8] Adambounou, K., Farin, F., Boucher, A., Adjenou, K.V., Gbeassor, M., N'dakena, K., et al. (2012) Real-Time Ultrasoundtele-Expertise System and Real-Tele-Diagnosisul Trasound Delayed Time. Pilote Study in Togo. Médecine et Santé Tropicale, 22, 54-60.

[9] Zeh, O.F., Goujou, E.G., Momo, S., Medza, J.O., Ngodo, C.S.R. and Ongolo, P. (2017) The Impact of the Use of Structured Worksheet on the Quality of the Second Term Obstetrical Ultrasound in Four University Teaching Hospital in Yaoude. Health Sciences and Diseases, 18, 26-30.

[10] Groupe de travail SFR_CRR (2007) General Recommendations for the Development of a Radiological Report. Journal de Radiologie, 88, 304-306. 